Article

\title{
Analytic Modeling of Vehicle Fuel Consumption
}

Michael Ben-Chaim ${ }^{1}$, Efraim Shmerling ${ }^{2}$ and Alon Kuperman ${ }^{3, *}$

1 Department of Mechanical Engineering and Mechatronics, Ariel University Center of Samaria, Ariel 40700, Israel; E-Mail: michailbc@ariel.ac.il

2 Department of Computer Science and Mathematics, Ariel University Center of Samaria, Ariel 40700, Israel; E-Mail: efraimsh@ariel.ac.il

3 Department of Electrical Engineering and Electronics, Ariel University Center of Samaria, Ariel 40700, Israel

* Author to whom correspondence should be addressed; E-Mail: alonku@ariel.ac.il; Tel.: +972-3-906-6239; Fax: +972-3-906-6238.

Received: 25 September 2012; in revised form: 19 December 2012 / Accepted: 24 December 2012 / Published: 4 January 2013

\begin{abstract}
An analytical method of evaluating vehicle fuel consumption under standard operating conditions is presented. In the proposed model, vehicle fuel consumption is separated into two different operating modes: cruising at constant speed and acceleration. In each of these modes fuel consumption is calculated based on the instantaneous engine efficiency, approximated using an analytical function rather than typically considered consumption map. The approximation is based on speed-power decoupling, employing two single dimension polynomials instead of a two-dimensional lookup table. The adequacy and accuracy of the model is verified using experimental calculations. Moreover, it is shown that the effect of various design parameters on vehicle fuel consumption can be studied utilizing the proposed model.
\end{abstract}

Keywords: road vehicle; driving cycle; fuel economy; modeling

\section{Introduction}

Evaluating fuel efficiency is an important procedure during ground vehicle design and operation. Based on this evaluation, usually performed via mathematical modeling and simulation, the main construction parameters of the vehicle may be determined at the design stage and steps to reduce fuel 
consumption may be taken. Since one of vehicle design main goals is minimizing fuel consumption for expected operating conditions, development of analytical models that allow accurate prediction of vehicle consumption appears to be highly desirable.

A well-known approach to estimating fuel consumption is inverse simulation [1-4], where the driving cycle-to-tank chain is represented by power transferring functional blocks with predetermined efficiency, as shown in Figure 1.

Figure 1. Inverse simulation flow. $v(t)$-driving speed versus time (driving profile); $g(t)$ —road grade versus time (driving profile); $P_{\text {mech }}(t)$-mechanical power on the wheel; $\omega_{w}(t)$ - wheel angular speed; $T_{w}(t)$-mechanical torque on the wheel; $r(t)$-gear ratio; $\omega_{e}(t)$ —engine speed; $T_{e}(t)$ —engine torque; $g_{e}(t)$ —specific fuel consumption.

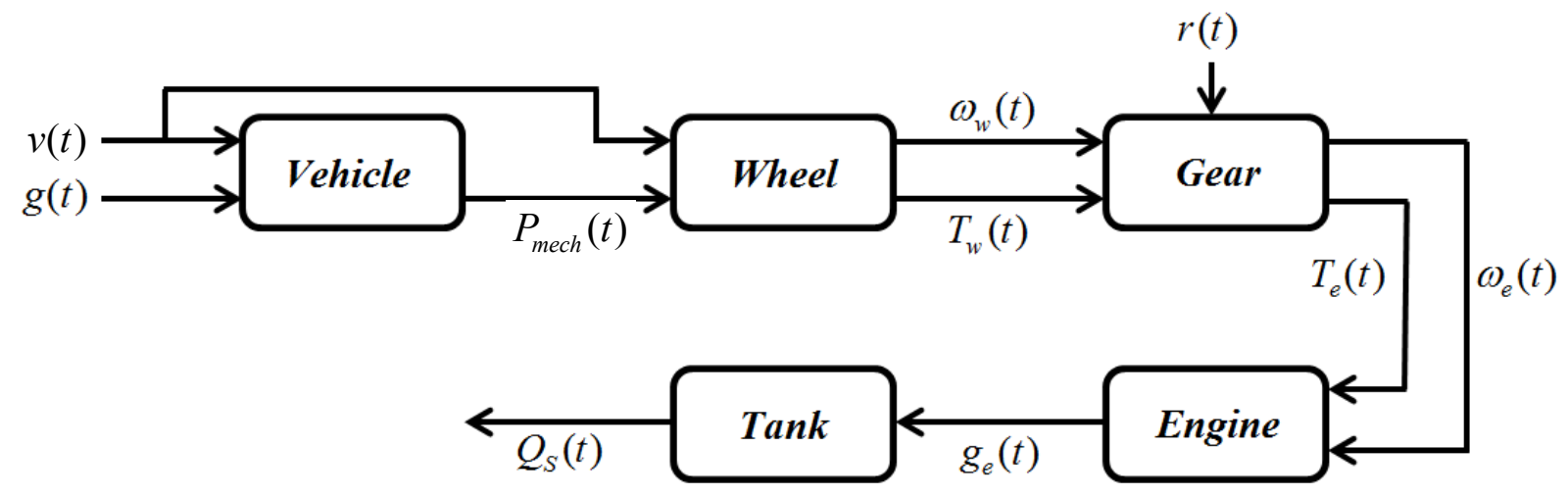

Engine specific fuel consumption is presented for illustration in Figure 2. It is usually represented by an appropriate two-dimensional lookup table, rather than obtained analytically. Alternatively, a similar two-dimensional map is often used for expressing engine efficiency rather than specific fuel consumption. Hence, simulation software must be used in order to determine the vehicle mileage. It would be more convenient if the fuel consumption could be determined from analytic expressions as much as possible, reducing the dependence on empirical simulation.

Figure 2. Typical internal combustion engine specific fuel consumption map [3].

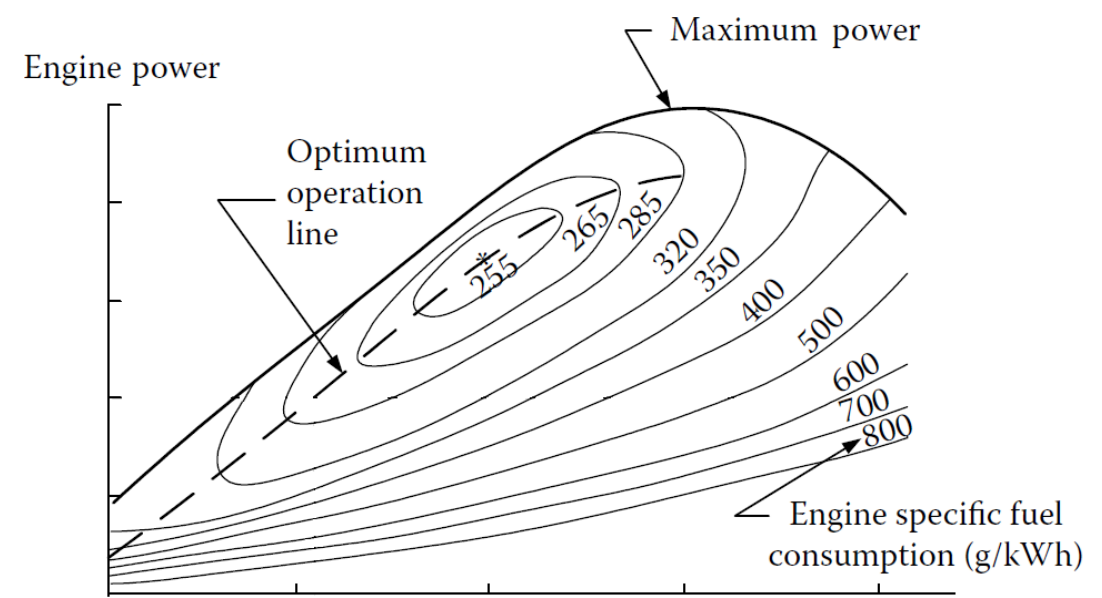

Engine speed 
Attempts for creating mathematical models for estimating fuel efficiency have been widely made in the literature. For example, it was proposed in $[5,6]$ to evaluate fuel consumption $Q_{S}$ measured in liters per $100 \mathrm{~km}$ via the following relation:

$$
Q_{S}=\frac{g_{e} \cdot\left(P_{r l}+P_{w}+P_{a}\right)}{10 \cdot V_{a} \cdot \eta_{T} \cdot \rho_{f}},
$$

where $g_{e}$ is the optimal specific fuel consumption, $\mathrm{g} \cdot \mathrm{kWh}^{-1} ; P_{r l}$ is the power required to overcome the rolling resistance of the road, $\mathrm{kW} ; P_{w}$ is the power required to overcome the resistance of the air, $\mathrm{kW}$; $P_{a}$ is the power required to overcome the resistance of the inertial acceleration, $\mathrm{kW} ; \eta_{T}$ is the efficiency of the transmission; $\rho_{f}$ is the fuel density, $\mathrm{kg} \cdot \mathrm{L}^{-1} ; V_{a}$ is the average speed of the vehicle, $\mathrm{km} \cdot \mathrm{h}^{-1}$.

Equation (1) assumes that the specific fuel consumption is constant and minimal. In [7,8] it is proposed to calculate fuel consumption based on specific hourly fuel consumption and energy expenditure, while the authors of [2,3] have suggested determining energy expenditure based on a computer simulation software ADVISOR; good results were obtained for the qualitative analysis of fuel economy. Energy expenditure determination based on statistical modeling was proposed in [1-4].

Particularly noteworthy is the work of Guzzella et al. [3], where mechanical energy consumption of vehicles for the European Driving Cycle MVEG-95 was determined. The authors proposed the following relation:

$$
E_{M V E G-95} \approx A_{f} c_{D} \cdot 1.9 \cdot 10^{4}+m_{v} f_{r} \cdot 8.4 \cdot 10^{2}+m_{v} \cdot 10 \quad[\mathrm{~kJ} / 100 \mathrm{~km}]
$$

where $m_{v}$ is car mass, $\mathrm{kg} ; f_{r}$ is the rolling resistance coefficient; $c_{D}$ is the coefficient of aerodynamic resistance of the car; $A_{f}$ is the characteristic area of the car, $\mathrm{m}^{2}$.

The first term in the right-hand side of Equation (2) is the energy required for overcoming the resistance of the air, the second term is the energy required for overcoming the resistance of the road, and the third term is the energy required for overcoming the inertial acceleration.

Basically, the bottleneck of all the proposed approaches is the need to include an engine consumption map, which was overcome by assuming constant specific fuel consumption for all operating modes, which is obviously inaccurate. The current work is interesting from a methodological point of view, since an attempt is being made to analytically calculate energy expenditure and fuel consumption, taking into account the instantaneous specific fuel consumption, approximated by two generalized single dimension polynomial functions. In the literature, e.g., [9,10], multiple dependencies of fuel consumption are constructed based on experimental data (approximation), but their purpose is largely confined to analyzing the influence of various factors on the fuel consumption of a specific vehicle, not theoretical generalizations.

Currently, the major set of regulations governing vehicle operating modes for estimating fuel consumption of vehicles are the rules of the UN Economic Commission for Europe [11]. The above mentioned models and formulas for calculating fuel consumption, which do not take into consideration the changes in the mode of motion, are unfit for evaluating fuel consumption in accordance with the accepted regulations. Development of a mathematical model which can be used for this purpose is the main contribution of this article. 
The rest of the manuscript is organized as follows. In Section 2, the proposed model for calculating fuel consumption in accordance with UN ECE regulations is described. In this model fuel consumption is determined separately for two different vehicle operating modes: constant speed and accelerations.

In Section 3, verification of the adequacy and accuracy of the obtained formula is presented. To assess it, calculation of fuel consumption using the derived formula was carried out and the results were compared to experimental data provided by the manufacturers. In order to carry out calculations via the proposed formula, parameters common for all automobiles are first identified. The vehicle-specific parameters used are the type of engine, automobile mass, maximum power and shaft speed at maximum power. Based on the comparison of calculations carried out using the proposed model to data from the manufacturers, it is concluded that the proposed mathematical model is suitable for practical use.

The 4th section illustrates the possibilities opened up by the utilization of the proposed model. An analysis of the effect of various design and operational parameters on fuel consumption is carried out based on the model.

\section{Estimating Fuel Consumption}

A vehicle's energy expenditure on a flat road consists of three parts, the first one being the energy required for overcoming the resistance of the air, the second - the energy required for overcoming the resistance of the road, and the third - the energy required for overcoming the resistance of the inertial acceleration. As stated in the introduction, the automobile engine operates in two main modes, the first one of which is movement at constant speed, and the second is acceleration. The proposed equation for estimating fuel consumption takes these into account, neglecting the fuel consumption during decelerations. In addition, the transmission efficiency is assumed to remain constant.

The energy expenditure on a flat road $E_{S}$ is then expressed as a sum $E_{S}=E_{1}+E_{2}$, where $E_{1}$ is the energy required to overcome the forces of resistance on the $100 \mathrm{~km}$ interval [J], and $E_{2}$ is the kinetic energy required for episodic accelerations on the $100 \mathrm{~km}$ interval $[\mathrm{J}]$. The $100 \mathrm{~km}$ distance is divided into $I=I_{1}+I_{2}$ subintervals with $I_{1}$ being the number of constant speed movement subintervals and $I_{2}$ being the number of accelerations. For example, consider an ECE 15 urban driving profile [12], shown in Figure 3. The cycle distance and duration are $1.015 \mathrm{~km}$ and $195 \mathrm{~s}$, respectively; hence there are 98.52 cycles in $100 \mathrm{~km}$, lasting 78,000 s. Each cycle contains four constant (nonzero) speed subintervals and three accelerations, i.e., $I_{1}=400, I_{2}=300$ and $I=700$.

The first energy component is determined based on the assumption that the car consumes fuel only when moving over a certain distance at a certain speed and when performing a series of accelerations on that same interval. Fuel consumption during decelerations and idle mode are not taken into account. This assumption has little effect on the accuracy of the results, especially for extra-urban driving modes. 
Figure 3. Parameters for the ECE cycle [12].

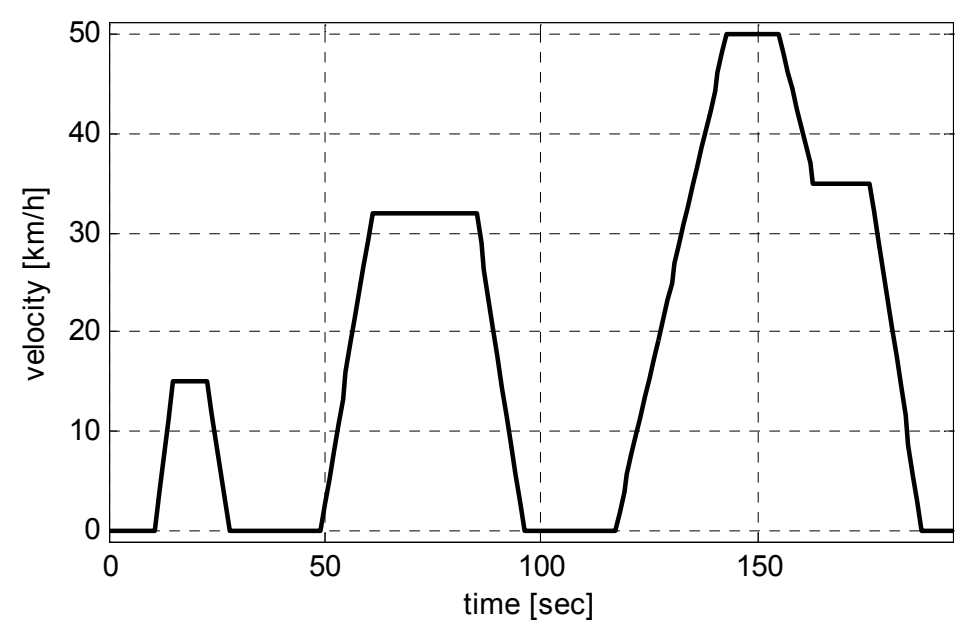

The resistance overcoming energies of each subinterval are summed up as:

$$
\begin{aligned}
E_{1}= & \frac{1}{\eta_{T}} \sum_{j=1}^{I_{1}} \frac{1}{\eta_{j}(P, n)}\left(m_{v} \cdot g \cdot f_{r} \cdot \frac{V_{j}}{3.6}+0.5 \cdot \rho_{a} \cdot C_{D} \cdot A_{f} \cdot\left\{\frac{V_{j}}{3.6}\right\}^{3}\right) T_{j}+ \\
& \frac{1}{\eta_{T}} \sum_{i=1}^{I_{2}} \int_{T_{i}} \frac{1}{\eta_{i}(P, n, t)}\left(m_{v} \cdot g \cdot f_{r} \cdot \frac{v_{i}(t)}{3.6}+0.5 \cdot \rho_{a} \cdot C_{D} \cdot A_{f} \cdot\left\{\frac{v_{i}(t)}{3.6}\right\}^{3}\right) d t[\mathrm{~J} / 100 \mathrm{~km}],
\end{aligned}
$$

where $\eta(P, n)$ is the engine efficiency, which depends on the degree of power utilization and of the engine speed mode; $\rho$ is air density, $\mathrm{N} \cdot \mathrm{s}^{2} \cdot \mathrm{m}^{-4} ; g$ is the acceleration of gravity, $\mathrm{m} \cdot \mathrm{s}^{-2} ; v_{i}(t)$ is the instantaneous vehicle speed at $i$-th acceleration subinterval, $\mathrm{km} \cdot \mathrm{h}^{-1} ; V_{j}$ is the vehicle speed at $j$-th constant speed subinterval, $\mathrm{km} \cdot \mathrm{h}^{-1} ; T_{j}$ is the $j$-th constant speed subinterval duration, $\mathrm{s} ; T_{i}$ is the $i$-th acceleration subinterval duration, $s$. In case rolling resistance coefficient and vehicle frontal area are not provided by the manufacturer, their approximate values may be estimated from the following empirical equations $[13,14]$ :

$$
f_{r}=0.0136+0.40 \cdot 10^{-7} v^{2}(t), \quad A_{f}=1.6+0.00056\left(m_{v}-765\right),
$$

with $v(t)$ being the instantaneous vehicle speed.

The energy required for increasing the kinetic energy during accelerations is determined via the following relation:

$$
E_{2}=\frac{m_{v} \cdot \gamma_{m}}{2} \sum_{i=1}^{I_{2}} \int_{T_{k}} \frac{a_{i}(t)}{\eta_{i}(P, n, t)} d t[\mathrm{~J} / 100 \mathrm{~km}],
$$

where $\gamma_{m}$ is the mass factor of the car, which equivalently converts the rotational inertia of rotating components into translation mass $[5,13] ; a_{i}(t)$ is the instantaneous vehicle acceleration at $i$-th acceleration subinterval, $\mathrm{m} \cdot \mathrm{s}^{-2}$.

Unlike Equation (1), in which the efficiency (or specific fuel consumption) of the engine is assumed to be constant, in the proposed formula it is a variable which depends on the degree of power utilization coefficient $\mu_{P}$ and the engine speed mode coefficient $\mu_{n}$ as follows. Define the peak efficiency of the engine at optimal mode as $\eta_{o}$. Hence the instantaneous engine efficiency is given by: 


$$
\eta(P, n)=\eta_{o} \mu_{P} \mu_{n}
$$

where $\mu_{P}$ is the coefficient through which the influence of the degree of power utilization on the efficiency of the engine is expressed, $\mu_{n}$ is the coefficient through which the influence of engine speed mode on the efficiency of the engine is expressed. In order to obtain the coefficients $\mu_{P}$ and $\mu_{n}$, the dependences $\mu_{P}=f\left(P_{i} / P_{e}\right)$ and $\mu_{n}=f\left(n_{i} / n_{p}\right)$ are determined as follows $\left(P_{i}, n_{i}\right.$ are instantaneous engine power and speed, respectively; $P_{e}$ is the maximum engine power, attainable at $n_{i} \mathrm{rpm}$, corresponding to performance characteristic of engine, and $n_{p}$ is the speed corresponding to engine rated power). Based on the performance characteristics of several different engines at full and partial loads, published by companies (e.g., Figure 3.31 in [13]) or available in the literature, specific fuel consumption was determined first, and then efficiency $\eta$ was calculated via well-known empirical relations $\eta=1 /\left(g_{e} \cdot 0.0122225\right)$ for gasoline engines and $\eta=1 /\left(g_{e} \cdot 0.0119531\right)$ for diesel engines. Companies also publish data on specific fuel consumption at partial loads (called motor control characteristics). The polynomials $\mu_{P}=f\left(P_{i} / P_{e}\right)$ and $\mu_{n}=f\left(n_{i} / n_{p}\right)$ are then obtained by splitting the consumption map (which is actually a three-dimensional surface of the form $\eta=f\left(P_{i} / P_{e}, n_{i} / n_{p}\right)$ into two two-dimensional vectors.

The above approach was used to carry out calculations of polynomials $\mu_{P}=f\left(P_{i} / P_{e}\right)$ and $\mu_{n}=f\left(n_{i} / n_{p}\right)$ for a number of modern car engines, whose characteristics were described in [15-19]. The results were then averaged and are shown in Figures 4 and 5. It was revealed that for the majority of diesel and gasoline engines $\mu_{P}=1$ when $P_{i} / P_{e}=0.8$, and $\mu_{n}=1$ when $n_{i} / n_{p}=0.7$ (see summary in Table 1 ).

Figure 4. Coefficient of the engine speed mode (same for diesel and gasoline engines).

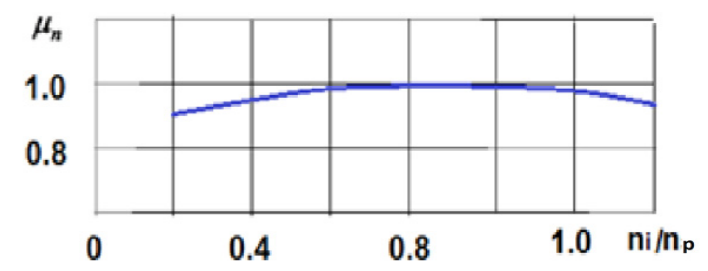

Figure 5. Coefficient of the power utilization.

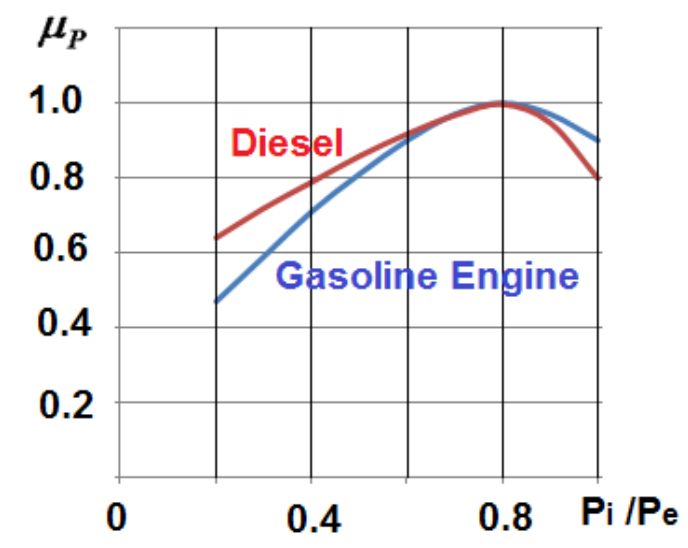


Table 1. Coefficient values.

\begin{tabular}{cccc}
\hline $\boldsymbol{P}_{\boldsymbol{i}} / \boldsymbol{P}_{\boldsymbol{e}}, \boldsymbol{n}_{\boldsymbol{i}} / \boldsymbol{n}_{\boldsymbol{p}} \boldsymbol{\%} \boldsymbol{\%}$ & $\boldsymbol{\mu}_{\boldsymbol{P}}$, Gasoline & $\boldsymbol{\mu}_{\boldsymbol{P}}$, Diesel & $\boldsymbol{\mu}_{\boldsymbol{n}}$ \\
\hline 0.20 & 0.47 & 0.64 & 0.87 \\
0.30 & 0.59 & 0.72 & 0.92 \\
0.40 & 0.71 & 0.79 & 0.96 \\
0.50 & 0.82 & 0.89 & 0.98 \\
0.60 & 0.90 & 0.92 & 0.99 \\
0.70 & 0.97 & 0.97 & 1.00 \\
0.80 & 1.00 & 1.00 & 0.99 \\
0.90 & 0.97 & 0.95 & 0.98 \\
1.00 & 0.90 & 0.80 & 0.96 \\
\hline
\end{tabular}

The graphical relationships of Figures 3 and 4 were further approximated by polynomials, and the following results were obtained. The relation for calculating $\mu_{P}$ for diesel engines is of the form:

$$
\mu_{P}=0.5968-0.1666\left(\frac{P_{i}}{P_{e}}\right)+2.4968\left(\frac{P_{i}}{P_{e}}\right)^{2}-2.1128\left(\frac{P_{i}}{P_{e}}\right)^{3},
$$

while $\mu_{P}$ for gasoline engines is calculated according to:

$$
\mu_{P}=0.234+1.0592\left(\frac{P_{i}}{P_{e}}\right)+0.8149\left(\frac{P_{i}}{P_{e}}\right)^{2}-1.2121\left(\frac{P_{i}}{P_{e}}\right)^{3} .
$$

The formula for calculating $\mu_{n}$ for diesel and gasoline engines is obtained as:

$$
\mu_{n}=0.7107+0.9963\left(\frac{n_{i}}{n_{P}}\right)-1.0582\left(\frac{n_{i}}{n_{P}}\right)^{2}+0.3124\left(\frac{n_{i}}{n_{P}}\right)^{3},
$$

Maximum attainable engine power at $n_{i}$ may be determined empirically as [1]:

$$
P_{e}=P_{P}\left[a\left(\frac{n_{i}}{n_{P}}\right)+b\left(\frac{n_{i}}{n_{P}}\right)^{2}-c\left(\frac{n_{i}}{n_{P}}\right)^{3}\right] \quad[\mathrm{kW}],
$$

where $P_{P}$ is the engine rated power and $a, b, c$ are engine (gasoline/diesel) specific constants. The instantaneous engine speed is proportional to the instantaneous velocity of the vehicle:

$$
n_{i}(t)=\frac{9.55 v(t) \xi_{a x} \xi_{n}}{r_{d}}
$$

with $r_{d}$ the rolling radius of the tire, $\mathrm{m} ; \xi_{a x}$ the final drive gear ratio; $\xi_{n}$ the gearbox gear ratio.

The resulting gasoline and diesel engine efficiencies are shown in Figures 6 and 7, respectively, demonstrating the power and speed dependencies.

The instantaneous engine power is determined from the overall resistance forces as:

$$
P_{i}=\frac{1}{\eta_{T}}\left(m_{v} \cdot g \cdot f_{r} \cdot \frac{v(t)}{3.6}+0.5 \cdot \rho_{a} \cdot C_{D} \cdot A_{f} \cdot\left\{\frac{v(t)}{3.6}\right\}^{3}+m_{v} \cdot \gamma_{m} \cdot a(t)\right)
$$

and fuel consumption per $100 \mathrm{~km}$ is given by: 


$$
Q_{S}=\frac{E_{s}}{H_{L}}=\frac{E_{1}+E_{2}}{H_{L}}[1 / 100 \mathrm{~km}]
$$

where $H_{L}$ is the calorific value of one liter of fuel, $\mathrm{J} \cdot \mathrm{L}^{-1}$.

Figure 6. Gasoline engines efficiency.

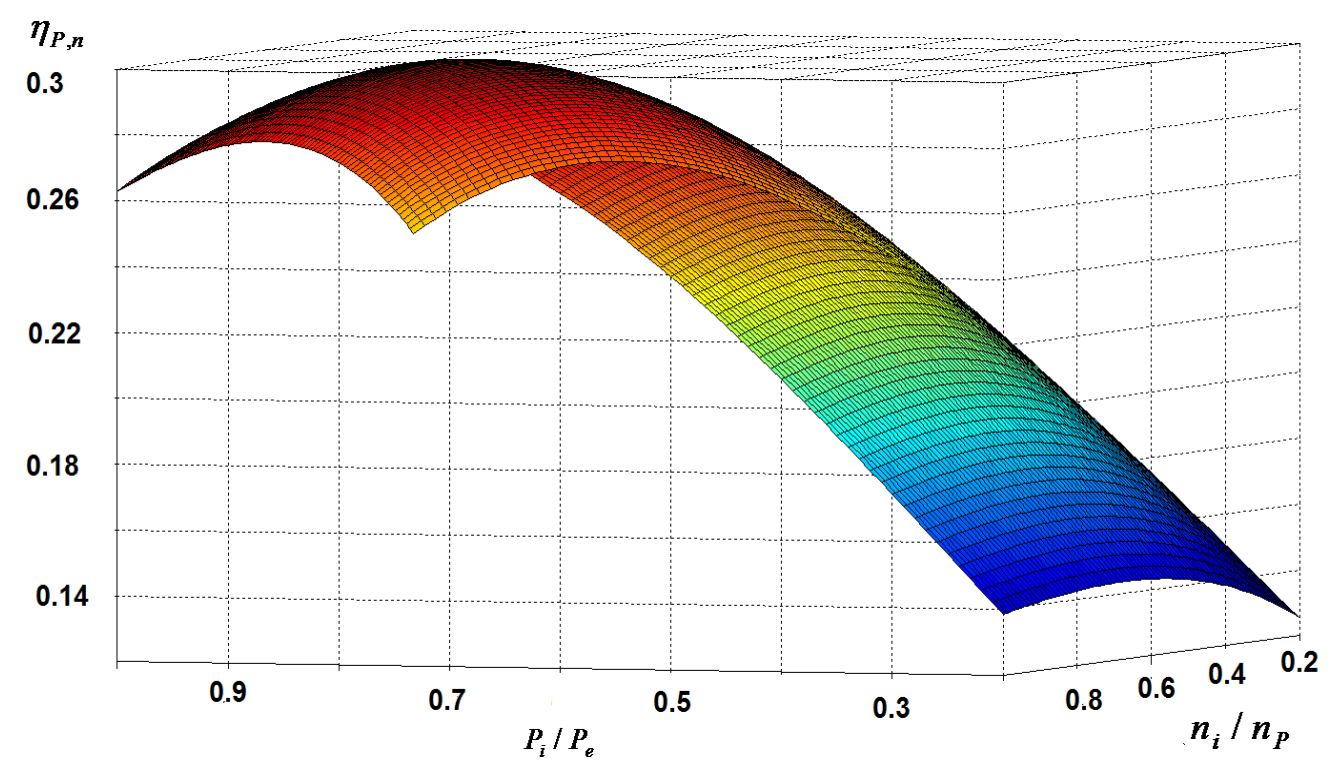

Figure 7. Diesel engines efficiency.

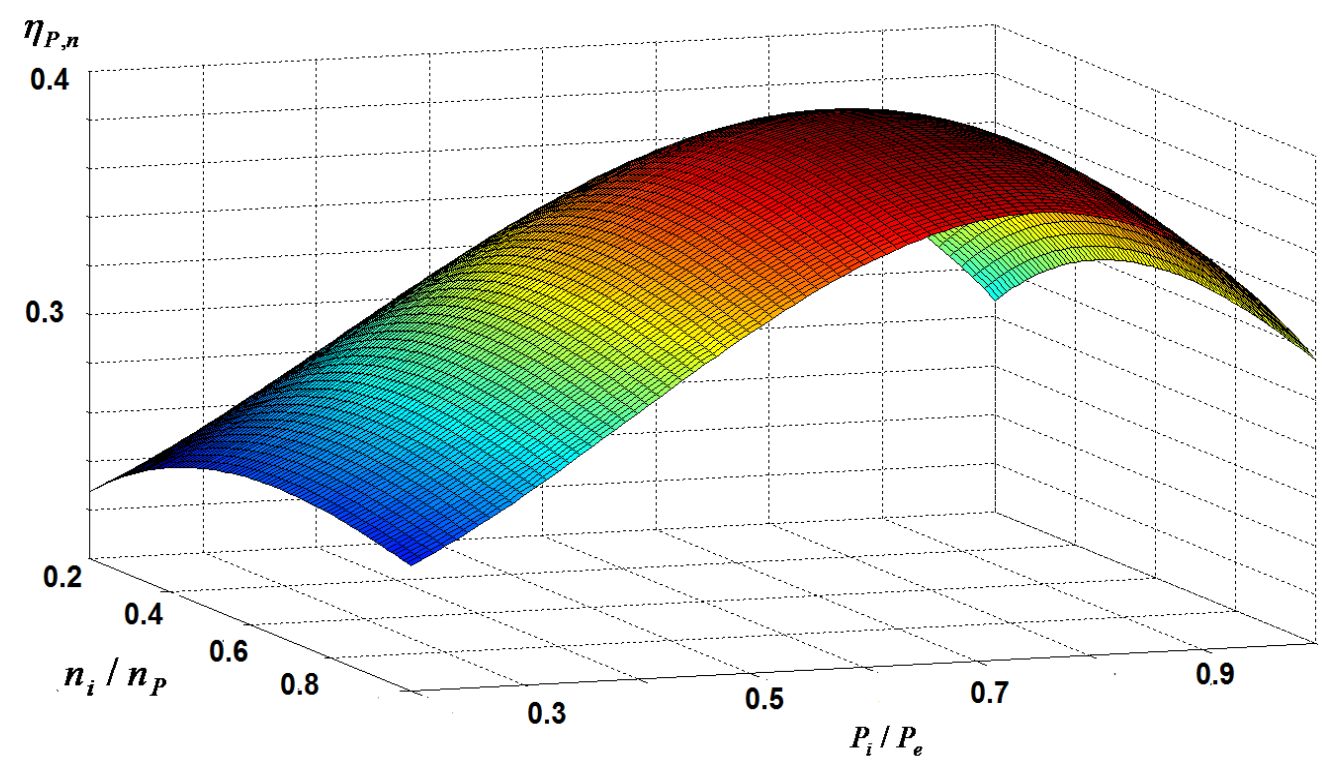

\section{Experimental Verification of the Derived Equations}

To assess the validity and examine the feasibility of the obtained formulas, calculations of fuel consumption were carried out using the derived expressions and compared to experimental data available from manufacturers [19]. In order to carry out the required calculations, common peak efficiencies $\eta_{o}$ where assumed as 0.4 for diesel engines and 0.3 for gasoline engines. The efficiency of the transmission $\eta_{T}$ was taken as 0.95 for both (see Table 2). The results of the comparison are given in 
Table 3. The vehicle-specific parameters used were the type of engine, automobile mass, rated power and engine speed.

Table 2. The values of common parameters used in our calculations.

\begin{tabular}{ccc}
\hline Engine & $\boldsymbol{\eta}_{\boldsymbol{e}}$ & $\boldsymbol{\eta}_{\boldsymbol{T}}$ \\
\hline Diesel & 0.40 & 0.95 \\
Gasoline & 0.30 & 0.95 \\
\hline
\end{tabular}

Table 3. Comparison results of vehicles fuel consumption.

\begin{tabular}{lccccccc}
\hline \multirow{2}{*}{ Vehicle } & \multicolumn{2}{c}{$\begin{array}{c}\text { Fuel consumption } \\
\text { (technical specifications) }\end{array}$} & $\begin{array}{c}\text { Fuel consumption } \\
\text { (calculated) }\end{array}$ & \multicolumn{3}{c}{ Vehicle parameters } \\
\cline { 2 - 6 } & \multicolumn{2}{c}{ Cycle } & \multicolumn{2}{c}{ Cycle } & Mass, \\
\cline { 2 - 6 } & EUDCE & URBAN & EUDCE & URBAN & $\begin{array}{c}\text { Rated } \\
\text { power, kW }\end{array}$ & $\begin{array}{c}\text { Rated } \\
\text { speed, rpm }\end{array}$ \\
\hline $\begin{array}{l}\text { Volkswagen Polo } \\
\text { Sedan }\end{array}$ & 4.8 & 7.7 & 4.9 & 7.4 & 1106 & 62.6 & 5000 \\
$\begin{array}{l}\text { Toyota Yaris } \\
\text { Toyota Sienna }\end{array}$ & 4.5 & 6.8 & 4.8 & 6.4 & 1005 & 73.1 & 6000 \\
$\begin{array}{l}\text { AWD } \\
\text { Toyota Camry }\end{array}$ & 10.7 & 14.7 & 11.2 & 15.5 & 2080 & 197.6 & 6000 \\
$\begin{array}{l}\text { AWD3.5 } \\
\text { Hyundai Genesis }\end{array}$ & 7.8 & 10.6 & 7.3 & 10.7 & 1570 & 196.9 & 6000 \\
$\begin{array}{l}\text { Coupé 2.0 T } \\
\text { BMW 1-Series }\end{array}$ & 8.4 & 10.2 & 7.5 & 10.8 & 1570 & 157.3 & 6000 \\
Convertible & 13.0 & 8.7 & 12.5 & 1400 & 170 & 6500 \\
\hline
\end{tabular}

As shown by Table 3, the disagreement between the results of calculations and the experimental data is in the $2 \%-7 \%$ range, indicating that the obtained formula provides a sufficiently good approximation.

\section{Effect of Design Parameters Variations on Fuel Consumption}

In order to examine the sensitivity of fuel consumption to various parameter changes, the derived expressions were utilized with ECE urban driving cycle. The obtained sensitivity coefficients are summarized in Table 4 together with nominal parameter values. The obtained results are in close agreement with the sensitivity coefficients available in the literature. 
Table 4. Sensitivity coefficients of fuel consumption to various design parameters.

\begin{tabular}{ccccc}
\hline Parameter & $\begin{array}{c}\text { Diesel nominal } \\
\text { value }\end{array}$ & $\begin{array}{c}\text { Diesel sensitivity } \\
\text { coefficient }\end{array}$ & $\begin{array}{c}\text { Gasoline } \\
\text { nominal value }\end{array}$ & $\begin{array}{c}\text { Gasoline sensitivity } \\
\text { coefficient }\end{array}$ \\
\hline$m_{a}, \mathrm{~kg}$ & 1000 & 0.13 & 1000 & 0.53 \\
$\eta_{e}$ & 0.40 & 1.3 & 0.30 & 0.80 \\
$\eta_{T}$ & 0.95 & 0.31 & 0.95 & 0.21 \\
$P_{P}, \mathrm{~kW}$ & 100 & 0.8 & 100 & 0.12 \\
$n_{P}, \mathrm{~min}^{-1}$ & 5000 & 0.72 & 6000 & 0.34 \\
$\zeta_{a x}$ & 3.5 & 0.05 & 3.5 & 0.03 \\
$\zeta_{n}$ & 1.0 & 0.071 & 1.0 & 0.06 \\
$r_{d}, \mathrm{~m}$ & 0.3 & 0.08 & 0.3 & 0.055 \\
$c_{r}$ & 0.015 & 0.14 & 0.015 & 0.25 \\
$V_{a}, \mathrm{~km} / \mathrm{h}$ & 62.2 & 0.19 & 62.2 & 0.06 \\
$(\rho / 2) c_{D}$, & 0.30 & 0.18 & 0.30 & 0.24 \\
$\left(\mathrm{~N} \mathrm{sec}{ }^{2}\right) / \mathrm{m}^{4}$ & 1.8 & 0.20 & 1.8 & 0.27 \\
$A_{f}, \mathrm{~m}^{2}$ & 1.08 & 0 & 1.08 & 0 \\
$\gamma_{m}$ & & & & \\
\hline
\end{tabular}

\section{Conclusions}

In this paper, an analytical approach to evaluating vehicle fuel consumption under standard operating conditions was described. Vehicle fuel consumption was separated into two different operating modes: constant speed and acceleration movements. In each mode, the fuel consumption was shown to be dependent on the instantaneous engine efficiency, approximated using two analytical functions instead of a typically considered consumption map. The approximation was based on speed-power decoupling, allowing employing two single dimension polynomials instead of a two-dimensional lookup table.

Fuel consumption was determined under the assumption that the vehicle consumes fuel only when moving over a certain distance at a certain speed and when performing a series of accelerations on that same interval. Fuel consumption during decelerations and idle mode were not taken into account. This assumption was shown to have a negligible effect on the accuracy of the results for extra-urban driving modes. For urban conditions the accuracy of the results is somewhat lower. Equations taking into account fuel consumption at idle will be presented in a future work.

The adequacy and accuracy of the model was verified using comparison with experimental manufacturer-provided data. Moreover, the sensitivity of vehicle fuel consumption to various design parameters changes was derived utilizing the proposed model.

It would be of merit in a future work to introduce fuel economy enabling technologies into the analysis such as start-stop feature, mild hybrid or full hybrid to determine how to advance vehicle economy best.

\section{References}

1. Froberg, A.; Nielsen, L. Efficient drive cycle simulation. IEEE Trans. Veh. Technol. 2008, 57, $1442-1453$. 
2. Wipke, K.; Cuddy, M.; Burch, S. Advisor 2.1: A user-friendly advanced powertrain simulation using a combined backward/forward approach. IEEE Trans. Veh. Technol. 1999, 48, 1751-1761.

3. Guzzella, L.; Sciarretta, A. Vehicle Propulsion Systems; Springer Verlag: Berlin, Germany, 2007.

4. Gaevsky, V.; Ivanov, A. Theory of Ground Vehicles; MADI: Moscow, Russia, 2007.

5. Kravets, V. Theory of Vehicles Handbook; University of Nizhni Novgorod, NNSU: Nizhni Novgorod, Russia, 2007.

6. Ross, M. Fuel efficiency and the physics of automobiles. Contemp. Phys. 1997, 38, 3-10.

7. Ehsani, M.; Gao, Y.; Emadi, A. Modern Electric, Hybrid Electric and Fuel Cell Vehicles: Fundamentals, Theory and Design, 2nd ed.; CRC Press: Boca Raton, FL, USA, 2010.

8. Tong, H.; Hung, W.; Cheung, C. On-road motor vehicle emissions and fuel consumption in urban driving conditions. J. Air Waste Manag. Assoc. 2000, 50, 543-554.

9. Widodo, S.; Hasegawa, T.; Tsugawa, S. Vehicle fuel consumption and emission estimation in environment-adaptive driving with or without inter-vehicle communications. In Proceedings of IEEE Intelligent Vehicles Symposium, Dearborn, MI, USA, 3-5 October 2000; pp. 382-386.

10. Al-Momani, W.; Badran, O. Experimental investigation of factors affecting vehicle fuel consumption. Int. Jour. Mech. Mat. Eng. 2007, 2, 180-188.

11. United Nations Economic Commission for Europe (UNECE). Vehicle Regulations. Available online: http://www.unece.org/trans/main/welcwp29.html (accessed on 1 August 2011).

12. Wong, J.Y. Theory of Ground Vehicles; John Wiley and Sons: Ontario, Canada, 2000.

13. Mitschke, M.; Wallwntowitz, H. Dynamik der Kraftfahrzeuge; Springer: Berlin, Germany, 2004.

14. Bosch, R. Bosch Gasoline-Engine Management; Bentley Pub: Cambridge, MA, USA, 2004.

15. Stone, R. Introduction to Internal Combustion Engines; Macmillan: Basingstoke, UK, 1985.

16. Jimenez-Palacios, J. Understanding and Quantifying Motor Vehicle Emissions and vehicle Specific Power and Tildas Remote Sensing. Ph.D. Thesis, Massachusetts Institute of Technology, Cambridge, MA, USA, February 1999.

17. Heywood, J. Internal Combustion Engine Fundamentals; McGraw-Hill, Inc.: New York, NY, USA, 1988.

18. Ferguson, C.R.; Kirkpatrick, A.T. Internal Combustion Engine: Applied Thermosciences, 2nd ed.; John Wiley and Sons: New York, NY, USA, 2001.

19. Speed Kills: Testing MPH vs. MPG in Top Gear. Available online: http:/www.metrompg.com/ posts/speed-vs-mpg.htm (accessed on 2 August 2006).

(C) 2013 by the authors; licensee MDPI, Basel, Switzerland. This article is an open access article distributed under the terms and conditions of the Creative Commons Attribution license (http://creativecommons.org/licenses/by/3.0/). 